\title{
HUMAN GEOGRAPHY WITH OPEN GIS AS A TRANSFORMATIVE INTRODUCTORY HIGHER EDUCATION COURSE
}

\author{
Joseph Holler ${ }^{1, *}$ \\ ${ }^{1}$ Department of Geography, Middlebury College, 287 Bicentennial Way, Middlebury VT 05753, USA - josephh@middlebury.edu
}

Commission IV, WG IV/4

KEY WORDS: critical GIS, open-source GIS, higher education, QGIS

\begin{abstract}
:
Curricula in human geography and GIS can integrate open-source GIS with critical human geography, moving beyond a curricular divide between critical human geography and technical GIS. This integration requires significant transformation of GIS curricula, requires students to simultaneously develop fundamental knowledge of both GIS and human geography to critically address spatial problems in society, and calls for transformation of GIS technology itself. The curriculum is transformed to teach GIS fundamentals experimentally through video tutorials and handouts, teach GIS problem-solving with error detection and debugging skills, teach human geography concepts by reading and replicating research papers, and apply critical human geography concepts and opensource GIS techniques to solve novel problems. Students develop skills in assessing error and uncertainty in GIS, applying GIS to solve human geography problems, and questioning the powerful interactions between politics, economics, and geospatial technologies. GIS technology is transformed as instructors develop software features to facilitate human geography inquiry for novice GIS students and students apply their new problem-solving skills to identify bugs and consider new GIS features.
\end{abstract}

\section{INTRODUCTION}

Previous reviews of GIS curricula have found a divide between critical human geography and GIS (Holler, 2019; St. Martin and Wing, 2007), paralleling a divide within the discipline (Schuurman, 2000). Many geographers question the validity and necessity of this divide, suggesting that a new field of knowledge production in critical GIS can integrate critical theory (e.g. drawing from feminist geography, science and technology studies, radical geography, or political ecology) with technical GIS knowledge and methods. Such integration can advance knowledge of GIS as a powerful technology in society, a product of powerful social relations, and a method extensible for innovative critical inquiry (O'Sullivan, 2006; Sheppard, 2005; Thatcher et al., 2016).

Higher education GIS curricula too often lack both critical and open GIS, presenting GIS as an infallible uncontested technology, linearly progressing in its development and limitlessly expanding its commercial applications (St. Martin and Wing, 2007). GIS curricula are not only missing critical human geography perspectives; they are also often missing more pragmatic geographic information science (GIScience) topics of alternative (open-source) software and data options, open standards, ethics, metadata, error, and uncertainty (Holler, 2019; Wikle and Fagin, 2014). Open source GIS presents opportunities to destabilize mainstream representations of GIS as commercial and infallible, investigate the history and social context of GIS development, expand access to GIS by marginal social groups or grassroots movements, encounter data errors and software bugs and participate in fixing them, and develop open GIS for critical and qualitative human geography research (Cope and Elwood,
2009; Garnett and Kanaroglou, 2016; Rey, 2009; Sieber, 2004; Sui, 2014).

Compared to black-boxed proprietary software, open-source GIS provides opportunities for students and faculty to engage more deeply with GIS technology, more extensively with a social community of developers and users, and with an alternative political economy of knowledge production (Rey, 2009; Sui, 2014). The depth and minutiae of data structures and algorithms is transparent in open-source code, so students will not be limited by proprietary secrets or licenses. Wikis, issue forums, and code repositories connect developers with each other and with users. Intellectual work of developing open geographic data and software algorithms is considered a common resource for public good, and peer review is fast and transparent. A critical open GIS curricula therefore empowers students to begin engaging with a global community of geographic analysis and knowledge production from an introductory level.

Open-source GIS is therefore amenable and accessible to the forms of social critique, methodological innovation, and grassroots participation valued by critical GIS scholarship. Open-source GIS enables critical GIS scholars to move beyond the opaqueness of black-boxed proprietary software to know GIS more intimately as a research subject (Schuurman and Pratt, 2002). The ethos of free source code access and (re)distribution implies that open GIS can be applied and repurposed without the restrictions of expensive licenses or rigidly encoded modes of knowledge representation and decision-making, alleviating concerns amongst critical GIS scholars working with qualitative data (Cope and Elwood, 2009; Garnett and Kanaroglou, 2016) and in contexts of

* Corresponding author 
international development (Dunn et al., 1997) and grassroots urban movements (Elwood, 2001).

Recent free and open-source software for geospatial (FOSS4G) papers have illustrated how open-source GIS applications in higher education can transform curricula, students, partnering private and public sector organizations, and even geospatial data and technology. Open source GIS is more sustainable and amenable to entrepreneurship for Tanzanian universities and students (Käyhkö et al., 2018). Students practicing OpenStreetMap humanitarian mapping gain experience in image interpretation, digitization, and understanding spatial data error while expanding their social networks and major and career aspirations (Coetzee et al., 2018). Open-source software provides platforms for collaboration between universities and public and private-sector partners in case-based learning (Minghini et al., 2017). Students digitize and edit open geospatial data through humanitarian mapping exercises (Coetzee et al., 2018). Open GIS standards and software libraries provided a base with which doctoral students developed an open city toolkit for citizen participation in smart and open city governance (Granell et al., 2018). FOSS4G, in sum, is expanding possibilities in GIS curricula for case-based learning, open cities, entrepreneurship, and applications in developing countries. It is expanding the number and diversity of students accessing GIS, the social relationships and partnerships through which they learn, and the breadth of skills and potential career paths they are exposed to. Finally, FOSS4G is also changing, in the development of OpenStreetMap humanitarian data and open city toolkits.

This paper follows previous work developing an advanced critical and open GIS course with thematic focus on environmental and demographic change in developing countries (Holler, 2019). Responses to that work questioned whether integration would also be possible at the introductory level, and this paper answers affirmatively: yes. The following section gives an overview of the re-designed introductory GIS course. Open-source GIS has proven to be both a liability and an asset in this effort, and the following section discusses how the course is responding to and beginning to transform opensource GIS. Following Coetzee and others (2018), I discuss how this effort has transformed not only GIS curricula, but also the students and open GIS itself.

\section{COURSE DESIGN}

The course, Human Geography with GIS, is taught at a small liberal arts undergraduate college, and is a core requirement for majors in geography and environmental studies with no prerequisites. The course subordinates GIS techniques within the broader goal of teaching how human geographers study spatial patterns of human activity and interactions with the environment, and it uses exclusively free and open-source software. Techniques are taught using the vector GIS model with QGIS (QGIS Development Team, 2019) and numerous plugins, including QuickMapServices and QuickOSM to access imagery and OpenStreetMap data (OpenStreetMap Contributors, 2019), Data Plotly for graphing, and QNEAT3 for network analysis.

\subsection{Learning Goals}

The learning goals prioritize fundamental human geography concepts and critical perspectives, framing GIS as one method of representing and analysing data for research in human geography. The learning goals are to:

- Understand, use, and articulate concepts that are fundamental to a geographical perspective, such as scale, region, location, space, distance, and spatial interaction.

- Critically examine a range of thematic problems and recognize geographic dimensions of contemporary issues. Understand and critique how geographic information systems are used in human geography research and realworld applications.

- Develop and use basic geographic skills such as map reading, cartography, and spatial analysis. Critically interpret and evaluate maps and other forms of locationbased data.

- Given geographic questions and data sets, select and implement appropriate methods to answer the questions. Effectively communicate your methods and findings through diagrams, maps, and narrative.

- Become familiar with using geographic information systems and learning new GIS techniques.

- Conduct GIS research with appreciation for the importance of error, uncertainty, and ethics.

The learning goals reflect a course structured to progress from fundamental concepts and techniques to surveying a variety of themes and problems, to eventually solving problems and accomplishing research goals more independently.

\subsection{Structure of the Course}

The macro-level structure of the course begins with an introduction to geography, GIS, and cartography from perspectives of critical mapping and GIScience (Crampton, 2010; Schuurman, 2004) and progresses through urban geography (Nelson et al., n.d.; Poulsen et al., 2001), urban political ecology and environmental justice (Heynen et al., 2006). In the fifth week, students break from new content for a week to complete an independent exam. We then venture into vignettes of hazards geography paired with map projections before surveying political geography of gerrymandering (Forest, 2005; Horn et al., 1993), population and health geographies of settlement patterns and health care access (Meade and Emch, 2010; Rodrigue, 2017; Tansley et al., 2015), and a second independent exam.

The micro-level structure of the course is designed to use a schedule of Tuesday and Thursday lectures and Wednesday labs to help students master human geography and GIS fundamentals and conceptually navigate between observations of the referent milieu, and abstractions in GIS data, cartography, and human geography theory and models (Head, 1991; Sui, 1995).

Beginning with the latter half of Thursday lectures, students are introduced to a new sub-discipline of human geography by surveying types of spatial questions and GIS applications, often returning to urban questions in Central Falls, Rhode Island and to regional and rural questions in Vermont.

Over the weekend, students complete video tutorials of simple worked examples experimenting with new techniques in QGIS, completing handouts and questions to ensure comprehension of technical fundamentals. Whenever possible, tutorials guide students to digitize and manipulate extremely simplified 
sample data for the same cases and questions discussed in lecture, helping students connect human geography questions about the milieu with abstract data representations and algorithms in GIS. Weekend readings introduce a case of human geographers applying GIS with research questions, data sources, and techniques compatible with the lecture and tutorial.

Tuesday lectures reaffirm fundamentals learned over the weekend and discuss how GIS techniques can be combined to solve a real research problem, as demonstrated by the weekend reading. By the end of Tuesday lecture, a lab problem for Wednesday is introduced, challenging students to translate what they have learned to a novel situation.

During Wednesday labs, students work interactively with each other and instructors to solve the novel GIS problem. By the end of lab, students complete a short set of questions to guide discussion of results at the beginning of Thursday's lecture.

The micro-level structure of a week of instruction is repeated for three to five weeks, building experience and a set of concepts and techniques before breaking into an independent exam. The course's structural integration of critical human geography with open source GIS is exemplified by activities of the first weeks of the course, following a slightly modified routine to accommodate the beginning of the semester.

\subsection{Wheelchair Users' Mobility on Campus}

Students embark on an introduction to human geography, GIS, and cartography with a two-week radical cartography project mapping wheelchair users' perspective of (im)mobility in the built environment, reading Kitchin's (2002) "Participatory Mapping of Disabled Access". In the first lab, students form small groups and follow the research paper's methodology with the guidance of a detailed handout and facilitators. They develop a set of cartographic symbols, an associated data schema, and a Google Form for data collection based on a guide to data measurement levels and visual variables. Students then collect field data on campus, using smart phones to populate their Google Form with points of assets and barriers to wheelchair mobility. To collect locational latitude and longitude data, they use a Leaflet map with an OpenStreetMap base map and a panel exposing the data stream from their device's location services.

In the next lecture, students learn the fundamentals of measuring location: latitude, longitude, datum, geographic coordinate systems, Global Positioning Systems, precision and accuracy. Measurement of location is contextualized and contrasted with human geography concepts of location, space, sense of place, and appreciation of differentiated experiences of place and mobility.

Over the weekend, students learn to design a map of their wheelchair mobility data. They follow a video tutorial for importing their accessibility field data into QGIS and using QuickMapServices to add an OpenStreetMap base map. The tutorial concludes with visualizing accessibility data using visual variables of colour, symbol shape, and size.

The following Tuesday lecture introduces the vector GIS data model and cartographic principles of an intellectual hierarchy and visual hierarchy for map design. Both the data representation and map representation of space are contextualized by discussing GIS and cartography as a semiotic system (Head, 1991) in which both GIS data and map symbols are abstract and generalized symbols of the referent milieu. Student's maps are contrasted with official maps of campus with particular focus on the sets of symbols used and the features represented (or not) and a critical discussion about the discursive power of maps (Harley, 1989) - both to marginalize less powerful perspectives and to advocate for change.

The second lab completes the course introduction by designing a cartographic layout for their mobility data (Figure 1) and writing a caption to interpret the map through human geography and critical cartography concepts. Students are still novices with QGIS at this stage, so video tutorials help them to query reference features from OpenStreetMap using the QuickOSM plugin and design a print map layout.

The first two weeks function as a collaborative effort to demonstrate critical human geography research with GIS and cartography, and practice the skills in reading, GIS, data visualization, and critical interpretation that students will need for independent exams. Both Critical GIS perspectives and technical GIS knowledge are complementary and integral to the learning goals. Students' notions of maps and GIS data as singular objective and accurate representations of geographic space are incontrovertibly destabilized as they learn to construct alternative GIS databases and cartographic representations for wheelchair users. Students learn to be critical of their phone as a powerful sensor for surveillance as they use the stream of data provided by location services to collect location data and learn the fundamentals of GPS and location enhancement using Wi-Fi signals. Finally, class discussions illuminate how the built environment, GIS data, and maps area all products of powerful social relations which are differentially experienced by diverse individuals. Students are empowered by the realization that critical geographic analysis and cartography can enable new forms of engagement with, and development of, the built environment.

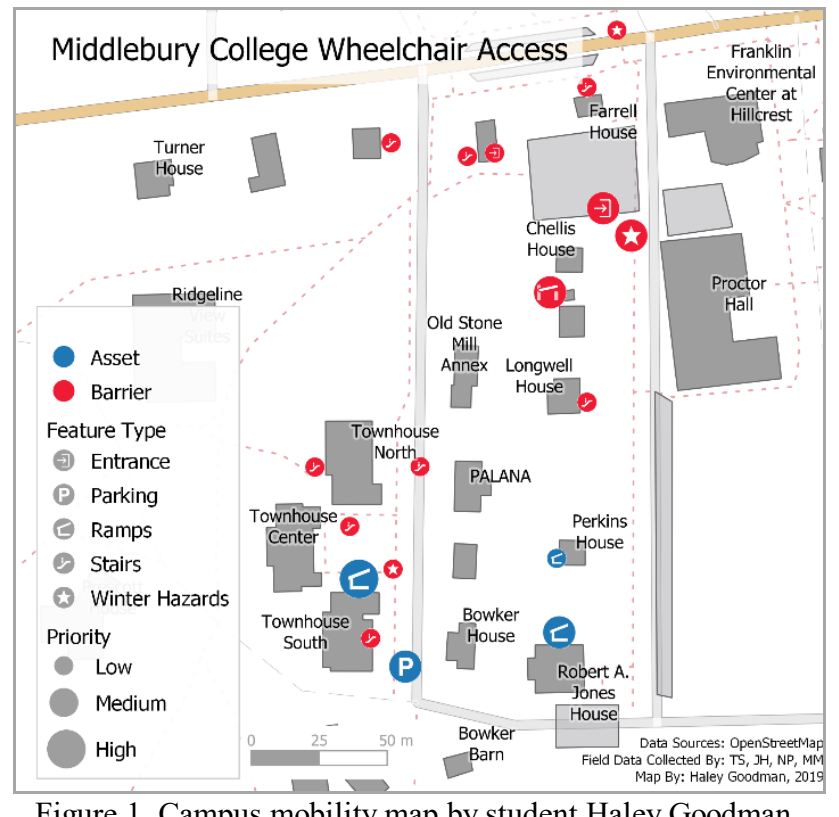

Figure 1. Campus mobility map by student Haley Goodman. Geographic reference features (C) OpenStreetMap Contributors. 


\subsection{Demonstrating and Evaluating Learning}

During instructional weeks of the semester, learning is evaluated through two short sets of electronic questions in a course management system. Questions follow the weekend video tutorials and the labs, and evaluate four things: recall and comprehension of human geography concepts, understanding GIS fundamentals, accurate completion of GIS analysis, and interpretation of GIS outputs.

Independent exams are given in three steps. First, a geographic question and GIS problem is posed and data sources available for solving the problem are described, including written metadata and video tours of the data. Students document a proposed GIS solution for the problem on paper and hand it in. Second, data is made available to students so that they can implement their solution with QGIS, after which they hand in answers and any revisions they made during implementation. Finally, correct answers and solutions to the GIS problem are presented so that students can learn through revising answers and develop a visual essay composed of figures (maps, graphs, and tables) and narrative captions to answer the geographic question. Exams are evaluated based on how much revision was necessary to achieve the correct GIS solutions, and how clearly and convincingly the visual essay communicates GIS results and interprets them with human geography concepts to answer the geographic question.

The first independent exam posed the question: is Harris County, Texas (containing the city of Houston) segregated, and if so, is there environmental injustice in exposure to extreme summer heat? Students were provided a $30 \mathrm{~m}$ resolution raster of surface temperatures derived from the Landsat 7 satellite on September 6, 2000, census data on race and median gross rent at the census block level, and instructions for viewing high resolution satellite imagery with the QuickMapServices plugin. Instructions prompted students to classify census blocks by types of segregation according to concentration of minority populations (Poulsen et al., 2001), analyse spatial distribution of median gross rent by direction and distance from the central business district, and calculate summary statistics of temperature by block group and segregation type.

The most successful students used series of choropleth maps and scatterplots to analyse the uneven spatial structure of rent (as a proxy for class), race, and temperature in Houston. They interpreted patterns of segregation using Burgess's (1925) concentric zone theory and Hoyt's (1939) sector theory. More critically, they recognized how redlining and recent gentrification create exceptions to the old models of urban structure, and how these processes translate into significant patterns of difference in the quality of the urban environment and intensity of its heat islands.

\section{TRANSFORMING OPEN GIS}

The goals of transforming curricula and students outlined above have inspired and facilitated three different pathways for transforming open GIS itself: developing new features for pedagogical purposes, identifying and resolving bugs though course development, and students' identification of bugs through their own problem-solving and error-checking.

\subsection{New features for pedagogical purposes}

I have modified open source GIS in four ways to facilitate learning. First, I wanted students to be able to use their own mobile devices to learn the basics of measuring location and creating spatial databases while manually recording latitude and longitude coordinates. Therefore, I programmed a simple Leaflet map (see Figure 2) to display an OpenStreetMap base map and a panel with data from the device's location services. The map had the additional pedagogical benefit of illustrating a base map of reference features in the field that students could learn to reproduce with QGIS in the lab.

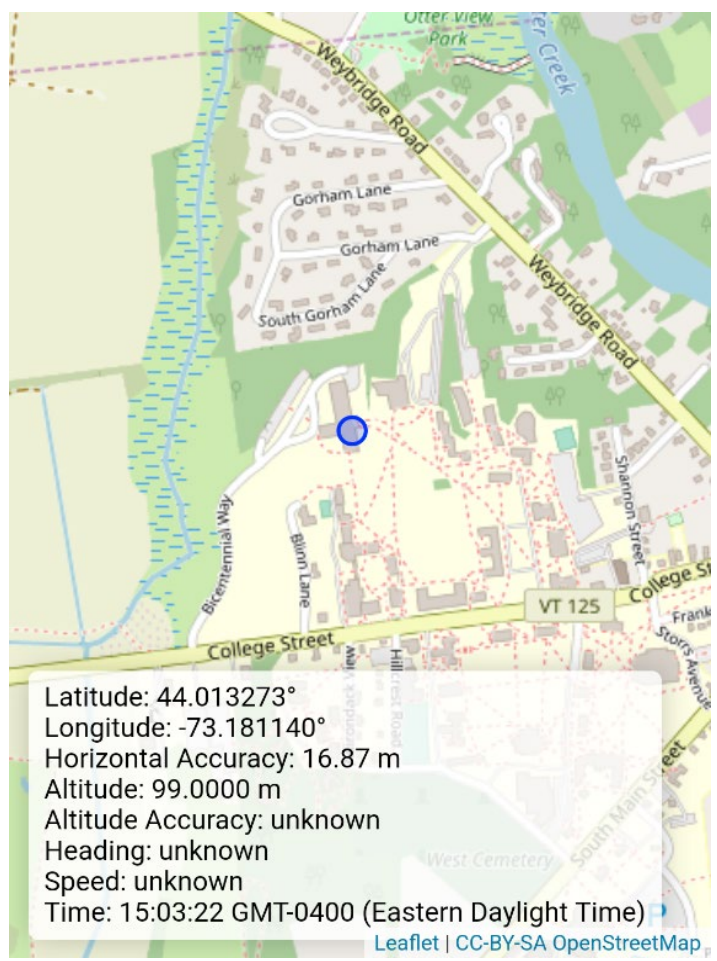

Figure 2: Leaflet map with location services for mobile devices at www.josephholler.com/maps.

Second, I found the core set of QGIS symbols limited in the context of conversations about the discursive power of legends and symbols in maps (Harley, 1989). A richer symbol set exists in the Maki scalable vector graphic (SVG) icons developed by Mapbox. Therefore, I modified the Maki SVG code to respond to fill colour controls in QGIS.

Third, I wanted students to be able to graph relationships between direction from the central business district (CBD) and rent in order to study Hoyt's (1939) sector model of urban structure. I facilitated the GIS analysis by creating a QGIS distance and direction algorithm to implement the field calculator azimuth and distance functions. Students initially used the Data Plotly plugin to create scatter plots, but ideally, direction from the CBD could be visualized in degrees on a polar plot rather than an $\mathrm{x}$-axis on a scatter plot. Therefore, I modified the Data Plotly plugin to map the $x$ variable with $r$ angular degrees and to reverse the polar plot to resemble the compass, starting at 0 degrees at top and increasing clockwise (Figure 3). 


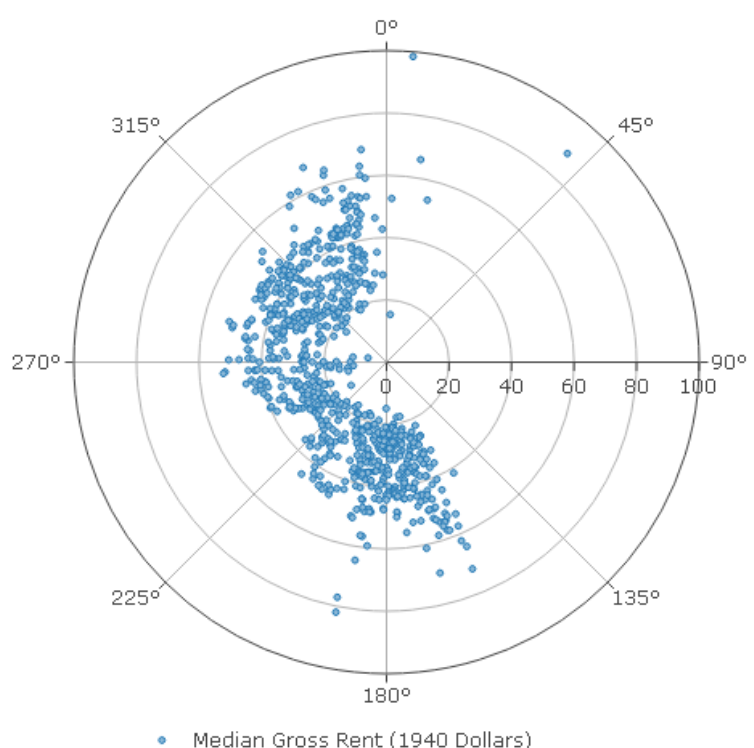

Figure 3: Rent by direction from Chicago's CBD in 1940; data from IPUMS NHGIS data (Manson et al., 2018)

Finally, the algorithms for dissolving features and calculating summary statistics in QGIS are sensitive to geometry errors, limited to one grouping field, and/or limited to one statistical summary field. Therefore, I prototyped a group by and dissolve algorithm using SQL. The algorithm makes input geometries valid, supports grouping by multiple fields, and supports calculating multiple statistics for multiple numerical fields.

The open source modifications discussed above are available on a GitHub site at https://github.com/GIS4DEV.

\subsection{Bugs discovered through course development}

I teach GIS fundamentals and techniques through simple experiments and examples using digitized inputs designed to illustrate boundary cases. Software bugs are therefore easy to identify. In the process of creating worksheet and video tutorials with QGIS version 3.4, I found two types of errors with the vector algorithms and saving outputs directly to GeoPackage database layers. Some algorithms were attempting to create both single-part and multi-part geometry types in the same table/layer (e.g. the buffer algorithm with the dissolve option) and some algorithms were violating unique id constraints by assuming that the FID from an input GeoPackage layer could be used directly as a unique id for an output GeoPackage layer (e.g. union and intersection). I reported the bugs and instructed students to work around them by first saving outputs to temporary layers. Both issues caused erroneous outputs and were quickly fixed by QGIS developers.

\subsection{Bugs Discovered by Students}

In tutorials and question sets, students practice the fundamentals and skills necessary to conceptualize correct outputs from GIS algorithms. In labs, they are prompted to practice checking their work for accuracy using feature counts, descriptive statistics, and inspection of outliers and boundary cases. Students' diligence enabled them to discover two minor bugs in the relatively new QNEAT3 plugin's network analysis algorithms. First, they found that the Origin-Destination Matrix results were missing one origin-destination pair, and this bug report was quickly resolved. Second, students encountered errors with the Iso-Areas algorithms, and through their own debugging discovered that the errors were caused by inconsistencies between the QGIS Project coordinate reference system (CRS) and the input network layer CRS. I have future plans to address this by adding code to check CRSs and to consistently use the CRS of the network input.

\section{DISCUSSION}

I have proposed that teaching critical human geography with open-source GIS has the potential to make the GIS lab into a space for transformation of curricula, of students, and of critical and open GIS research. Prior research and experience suggest this is possible at graduate (Granell et al., 2018) and advanced undergraduate (Holler, 2019) levels, but to what extent is it also possible at the introductory level?

\subsection{Transforming Curricula}

The transformational integration of critical human geography with open-source GIS techniques is possible for introductory courses focused on learning fundamentals of human geography and GIScience. The open-source aspect of FOSS4G is significant for this project and in many ways enacts the 'heterodox' GIS called for by St. Martin and Wing (2007) to destabilize the singular, infallible, commercialized, and universally applicable representation of GIS in mainstream curricula. Open source code enables a more intimate and technical knowledge of GIScience data structures and algorithms and their social construction over time. From students' perspectives, the most important difference is probably the accessibility and freedom afforded by open licenses to install and use the technology beyond the spatial limits of GIS labs, beyond the temporal limits of student or employment status, and with grassroots, non-profit, or entrepreneurial organizations.

Integration of human geography and open GIS also enables geography curricula to bridge human geography concepts and spatial analysis techniques from the introductory level. This is most clearly evident in students' performance in labs and independent exams. Introductory students solved complex GIS problems to quantify spatial injustices in mobility in the built environment, exposure urban heat islands, political gerrymandering, and access to health care services. Simultaneously, they interpreted results with human geography theory, critically reflected on limitations of their spatial analysis, and suggested both GIS and non-GIS approaches to improve their work. The hope is for this practice to translate into greater potential for this the cohort of students to propose and execute theoretically-informed senior research projects with spatial analysis as they progress through the geography major.

Finally, this course represents another step toward more thorough integration of critical GIS into geographic information science curricula. Although GIS and society and GIS ethics are recognized topics in the Geographic Information Science Body of Knowledge (DiBiase et al., 2006), the topics are too frequently left out of curricula focused on skills and techniques. Nonetheless, critical GIS scholarship has significant implications for any GIS practitioner, including frameworks to grapple with uncertainty, subjectivity, and ethics in spatial analysis. 


\subsection{Transforming Students}

Previous sections have already discussed students' success in achieving the learning goals of independent problem-solving through integration of human geography concepts and open GIS spatial analysis. Students have discovered bugs in software and critically discussed the capabilities, limitations and potential of GIS analysis in the context of human geography, but how did students perceive their own learning?

Student responses to the first version of the course were generally positive: 27 of 33 strongly agree and 5 agree that they "learned a great deal in this course". 19 strongly agree and 12 agree that "teaching in this course was effective." In qualitative responses, some students describe the beginning of a transformational learning experience leading toward ability to independently apply critical human geography and GIS to solve problems.

For example, the following three quotes exemplify a student with experience in qualitative investigation of social issues gaining confidence in application of critical spatial/quantitative analysis to the same issues, a student contextualizing the technical training within broader goals of problem framing and solving in critical human geography, and a student gaining interest and confidence in pursuing theoretical and technical geography work in the future.

- $\quad$ Learning GIS in many ways is like beginning to learn a language at Middlebury, when students are challenged to express their analytical understanding of problems within the context of a totally new software. Over the course of the semester, I have become proficient at using QGIS, figured out how to approach then solve human geography problems, and gained confidence that I could tackle some of the problems I had already thought about from a more qualitative perspective."

- $\quad$ "GIS has definitely improved my ability to think spatially and analytically, but also be able to think about the broader implications of my work. It incorporates social justice, creativity, and critical thinking."

- "This course had a phenomenal impact on my liberal arts education and interest in geography. Combining the practical and theoretical, I would often find myself practicing my GIS skills for fun with data sets that I could find. I anticipate using the skills in this course for years to come."

Although it is still early to determine the course's impacts on students' careers and future research interests, several students declared majors or minors in geography and many have subsequently pursued further courses, independent studies, and internships in GIS.

\subsection{Transforming Open GIS}

As a FOSS4G user and instructor of advanced courses, I have expected students to work around missing features or bugs through more advanced techniques or lengthy alternative workflows. Now teaching an introductory FOSS4G course, I am less tolerant, and reminded of calls for a "minimal GIS" with which to teach spatial thinking concepts in a simplified and reliable software environment (Marsh et al., 2007). The operational difficulties of using FOSS4G negatively impact student learning, as one student evaluation commented, "I was frustrated that little bugs seemed to hold me up more than anything else."

To facilitate analytical and spatial thinking and reduce the barriers of entry to learning GIS, the FOSS4G community might consider developing a minimal desktop GIS environment to parallel the QGIS project, incorporate instructional documentation, and gradually build up to the complexity of a full desktop GIS. FOSS4G has much to offer here: the code is open and malleable, and some algorithms are already much easier to use than alternatives. Contrast the complex user interfaces for network analysis in the most commonly used software for GIS education in the U.S. (Esri) with network analysis solutions attainable from a single algorithm with plugins like QNEAT3. With the goal of facilitating learning by novices, the plugin's user interface can be even further streamlined, and I have future plans to work on this.

I have mainly framed detecting and reporting bugs in FOSS4G as positive opportunities for problem solving and software development. This belies the stress of discovering unexpected bugs in the limited time available for new tutorial preparation on the part of instructors, or the stress of receiving unexpected errors on the part of students during labs or independent exams. Unexpected bugs require patience, time, and ingenuity to understand and overcome, and they disrupt the learning process for novice students. A common reprise in Open GIS conference panels is lack of recognition for code development and debugging in faculty career evaluations, so can faculty teaching FOSS4G afford the costs of doing so? At least one opportunity is to transform the software debugging and development work for an introductory course into teaching material for advanced courses in GIScience, but this is only a partial solution.

\section{CONCLUSIONS}

Two semesters of experimenting with an introductory open GIS and critical human geography course have led to encouraging results in transforming GIS curricula, students, and software. There are early signs that work from the course may even contribute to increased awareness and planning for wheelchair accessibility on campus. FOSS4G has been integral to this project: its open source code and global community of contributors has facilitated the integration of critical human geography and GIS.

These early successes came despite significant frustrations with software bugs and a dearth of published curricular materials for teaching integrated critical and open GIS, raising questions for future work required to sustain momentum in this effort. FOSS4G has potential for development of a minimal GIS tailored to introductory critical inquiry in human geography for simplicity and reliability, while building foundations for spatial analysis in open GIS. Therefore, next steps in development of this course will include development of streamlined network analysis algorithms, an open text with concise explanations of human geography concepts and GIS fundamentals, a bibliography of reading and worked examples of GIS applied for human geography research, and a paired set of video tutorials and exercises for learning fundamental techniques through experimentation and problem-solving. If successful, these steps will improve the quality and accessibility of GIS in higher education, and help cultivate a community of students becoming professionals with the ability 
to apply spatial analysis and human geographic theory to problems of social and spatial inequity.

\section{ACKNOWLEDGEMENTS}

I deeply appreciate the Fall 2018 and Spring 2019 students of Human Geography with GIS, Dr. Jeff Howarth for initiating innovative changes to Middlebury's GIS courses (including independent problem assessments and overall course structure), and to colleagues Bill Hegman and Lea LeGardeur for their patience and instructional support in the transition to FOSS4G.

\section{REFERENCES}

Burgess, E.W., 1925. The Growth of the City: An Introduction to a Research Project. Publ. Am. Sociol. Soc. XVIII, 85-97.

Coetzee, S., Minghini, M., Solis, P., Rautenbach, V., Green, C., 2018. Towards understanding the impact of Mapathons Reflecting on youthmappers experiences. Int. Arch. Photogramm. Remote Sens. Spat. Inf. Sci. - ISPRS Arch. 42, 35-42. https://doi.org/10.5194/isprs-archives-XLII-4-W8-352018.

Cope, M., Elwood, S. (Eds.), 2009. Qualitative GIS : a mixed methods approach. Sage, Los Angeles.

Crampton, J.W., 2010. Mapping: a critical introduction to cartography and GIS. Wiley-Blackwell, Malden, Mass.

DiBiase, D., DeMers, M., Johnson, A., Kemp, K., Luck, A.T., Plewe, B., Wentz, E. (Eds.), 2006. Geographic information science and technology body of knowledge. Association of American Geographers, Washington, D.C.

Dunn, C.E., Atkins, P., Townsend, J.G., 1997. GIS for Development: A Contradiction in Terms? Area 29, 151-159.

Elwood, S., 2001. GIS and Collaborative Urban Governance: Understanding Their Implications for Community Action and Power. Urban Geogr. 22, 737-759. https://doi.org/10.1080/02723638.2001.11501633.

Forest, B., 2005. The changing demographic, legal, and technological contexts of political representation. Proc. Natl. Acad. Sci. U. S. A. 102, 15331-15336. https://doi.org/10.1073/pnas.0507314102.

Garnett, R., Kanaroglou, P., 2016. Qualitative GIS : An Open Framework Using SpatiaLite and Open Source GIS. Trans. GIS 20, 144-159. https://doi.org/10.1111/tgis.12163.

Granell, C., Bhattacharya, D., Casteleyn, S., Degbelo, A., Gould, M., Kray, C., Painho, M., Trilles, S., 2018. GEO-C: Enabling open cities and the open city toolkit. Int. Arch. Photogramm. Remote Sens. Spat. Inf. Sci. - ISPRS Arch. 42, 61-68. https://doi.org/10.5194/isprs-archives-XLII-4-W8-612018.

Harley, J.B., 1989. Deconstructing the Map. Cartographica 26, 1-20.

Head, C.G., 1991. Mapping as language or semiotic system: review and comment, in: Mark, D.M., Frank, A.U. (Eds.), Cognitive and Linguistic Aspects of Geographic Space.
Springer, Dordrecht, pp. https://doi.org/10.1126/science.98.2556.564.

$237-262$.

Heynen, N., Perkins, H. a, Roy, P., 2006. The Political Ecology of Uneven Urban Green Space. Urban Aff. Rev. 42, 3-25.

Holler, J., 2019. Teaching critical open GIS. Can. Geogr. 00, 1-11. https://doi.org/10.1111/cag.12521.

Horn, D.L., Hampton, C.R., Vandenberg, A.J., 1993. Practical application of district compactness. Polit. Geogr. 12, 103-120. https://doi.org/10.1016/0962-6298(93)90031-2.

Hoyt, H., 1939. The Pattern of Movement of Residential Rental Neighborhoods, in: The Structure and Growth of Residential Neighborhoods in American Cities. Federal Housing Administration, Washington, D.C., pp. 112-122.

Käyhkö, N., William, C., Mayunga, J., Makame, M.O., Mauya, E., Järvi, A., 2018. Building geospatial competences in Tanzanian universities with open source solutions. Int. Arch. Photogramm. Remote Sens. Spat. Inf. Sci. - ISPRS Arch. 42, 93-99. https://doi.org/10.5194/isprs-archives-XLII-4-W8-932018.

Kitchin, R., 2002. Participatory Mapping of Disabled Access. Cartogr. Perspect. 44-54.

Manson, S., Schroeder, J., Riper, D. Van, Ruggles., S., 2018. IPUMS National Historical Geographic Information System. https://doi.org/10.18128/D050.V13.0.

Marsh, M., Golledge, G., Battersby, S., 2007. Geospatial concept understaning and recognition in G6-College students: A Preliminary argument for minimal GIS. Ann. Assoc. Am. Geogr. 97, 696-712.

Meade, M.S., Emch, M., 2010. Medical Geography. Guilford Press, New York, pp. 407-452.

Minghini, M., Brovelli, M.A., Vandenbroucke, D., Carbonaro, M., Prüller, S., Painho, M., Martirano, G., Frigne, D., 2017. FOSS4G as a key building block for case-based learning in geographic information education. Int. Arch. Photogramm. Remote Sens. Spat. Inf. Sci. - ISPRS Arch. 42, 129-135. https://doi.org/10.5194/isprs-archives-XLII-4-W2-129-2017.

Nelson, R.K., Winling, L., Marciano, R., Connolly, N., n.d. Mapping Inequality: Redlining in New Deal America. Am. Panor. https://dsl.richmond.edu/panorama/redlining. (Accessed 7 June 2019)

O’Sullivan, D., 2006. Geographical information science: critical GIS. Prog. Hum. Geogr. 30, 783-791.

OpenStreetMap Contributors, 2019. OpenStreetMap. https://www.openstreetmap.org. (Accessed 7 June 2019)

Poulsen, M., Johnston, R., Forrest, J., 2001. Intraurban ethnic enclaves: Introducing a knowledge-based classification method. Environ. Plan. A 33, 2071-2082. https://doi.org/10.1068/a34124.

QGIS Development Team, 2019. QGIS Geographic Information System. http://qgis.osgeo.org. (Accessed 7 June 2019) 
Rey, S.J., 2009. Show me the code: spatial analysis and open source. J. Geogr. Syst. 11, 191-207. https://doi.org/10.1007/s10109-009-0086-8.

Rodrigue, J.-P., 2017. The spatial organization of transportation, in: Rodrigue, J.-P., Comtois, C., Slack, B. (Eds.), The Geography of Transport Systems. Routledge, New York.

Schuurman, N., 2004. GIS : a short introduction. Blackwell Pub., Malden, MA.

Schuurman, N., 2000. Trouble in the heartland: GIS and its critics in the 1990s. Prog. Hum. Geogr. 24, 569-590.

Schuurman, N., Pratt, G., 2002. Care of the Subject : feminism and critiques of GIS. Gender, Place Cult. 9, 291-299. https://doi.org/10.1080/0966369022000003905.

Sheppard, E., 2005. Knowledge Production through Critical GIS: Genealogy and Prospects. Cartographica 40, 5-21. https://doi.org/10.3138/GH27-1847-QP71-7TP7.

Sieber, R.E., 2004. Rewiring for a GIS/2. Cartographica 39, 25-39.

St. Martin, K., Wing, J., 2007. The discourse and discipline of GIS. Cartographica 42, 235-248. https://doi.org/10.3138/carto.42.3.235-248.

Sui, D., 2014. Opportunities and impediments for open GIS. Trans. GIS 18, 1-24. https://doi.org/10.1111/tgis.12075.

Sui, D.Z., 1995. A pedagogic framework to link GIS to the intellectual core of geography. J. Geog. 94, 578-591. https://doi.org/10.1080/00221349508979371.

Tansley, G., Schuurman, N., Amram, O., Yanchar, N., 2015. Spatial access to emergency services in low- and middleincome countries: A GIS-based analysis. PLoS One 10, 1-13. https://doi.org/10.1371/journal.pone.0141113.

Thatcher, J., Bergmann, L., Ricker, B., Sullivan, D.O., Barnes, T.J., Imaoka, L.B., Burns, R., Davis, C., Kersten, E., Lally, N., Lin, W., Payne, W., 2016. Revisiting critical GIS. Environ. Plan. A 48, 815-824. https://doi.org/10.1177/0308518X15622208.

Wikle, T.A., Fagin, T.D., 2014. GIS Course Planning: A Comparison of Syllabi at US College and Universities. Trans. GIS 18, 574-585. https://doi.org/10.1111/tgis.12048. 